\title{
Behavioral Bias Within The Decision Making Process
}

Inga Chira, Jacksonville University, USA

Michael Adams, Jacksonville University, USA

Barry Thornton, Jacksonville University, USA

\begin{abstract}
Behavioral finance studies how subjective behavioral elements introduce distortions in the individual's decision-making process. The empirical study of systematic errors in cognitive reasoning and perception, and ultimately what these errors reveal about the individual's underlying thought processes, is often referred to as investor heuristics and biases. This paper investigates the cognitive biases and heuristics to which business students are subject. This was achieved by administering a questionnaire and collecting empirical evidence about both undergraduate and graduate business students' own perceptions of bias. The psychological phenomenon known as bias and its presence in human decision making, both financial and nonfinancial, will provide additional insight on the subject of investor irrationality and broaden the ideals of rationality assumed in classical financial theory.
\end{abstract}

\section{INTRODUCTION}

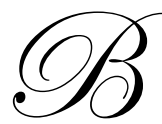

ehavioral Finance $(\mathrm{BF})$ is an emerging discipline that represents a collection of alternative approaches to refine the classical finance definition of economic rationality. In particular, BF draws on the psychology and cognitive science literatures to examine why individual decision-making often deviates from rational choices in systematic ways. Previous research on BF issues have focused on investor heuristics, biases, and framing effects. This paper will evaluate the existence and extent of a number of psychological phenomena that fall under the three above-mentioned categories. Specifically, it will analyze: excessive optimism and overconfidence, loss aversion, the influence of sunk cost on the decision making process, and the concept of familiarity. In addition, illusion of control and confirmation biases will be presented. Empirical evidence was collected by administering a 45 question survey to both undergraduate and graduate business students. The survey had the following purposes: (1) to identify the extent each of the above mentioned behavioral mistakes affect the decision making process for students and (2) to empirically measure the strength of the relationship between each mistake and educational level, risk aversion, and the degree of being extrovert/introvert.

A number of empirical anomalies or puzzles have been discovered in financial markets that are incongruent with what is generally regarded as the "rational behavior" expectation upon which the standard theory of finance is predicated. Systematic deviations from the precepts of normative finance and investor behavior are often referred to as bounded rationality, simply the human inability to logically evaluate decisions under conditions of uncertainty. As suggested by Toshino and Suto (2004), one potential criticism of BF is the fact that most of the experiments to check on the validity of its concepts have been done on campuses with students as participants. Thus, any behavioral conclusions derived from these experiments may be subject to the criticism that they simply wouldn't work in the actual securities marketplace, where sophisticated professionals are continuously making investment decisions. Perhaps more importantly, the observed anomalies in investor behavior give rise to alternative behavioral recognition of the manner in which a decision is framed and is an important element in any decision making process. Heuristics and investor biases often result in a chasm between theory and practice.

As Gene Epstein stated in "The Myth of Rationality: What Really Drives Economic Decisions" when referencing Kaufman (1994), "it is the nature of human behavior to try to escape discipline". When traditional 
finance fails to explain our lack of rationality, behavioral finance offers alternative explanations of what motivates economic decision-making. Do human beings think in terms of the past when developing their strategy for the future? Do they let themselves be influenced by the belief that they have control over a situation when there is no way to assess the amount of control? These are the types of questions that this paper will attempt to measure.

As defined by Hersh Shefrin, bias is nothing else but the "predisposition towards error" (Shefrin, 2007). In other words, a bias is a prejudice or a propensity to make decisions while already being influenced by an underlying belief. There are many common biases humans exhibit. This paper will address the following four: (1) excessive optimism, (2) overconfidence, (3) confirmation, and (4) illusion of control. In addition to biases, individuals often make decisions by engaging in other forms of psychological influences. The paper will look at the framing effect, which states that one's decision will be influenced by the way a particular issue is presented to him/her (Shefrin, 2007). Notably, loss aversion will be analyzed as the main concept under this category. Furthermore, the study will look at the impact of two other concepts that may undermine one's decision making process, the existence of the sunk cost fallacy and the familiarity heuristic.

Excessive optimism is related to the overestimation of the number of favorable outcomes in comparison to unfavorable ones (Shefrin, 2007). This particular bias is present in a wide variety of fields. For example, when it comes to the debt-equity ratio for financing, Meinert has pointed out that "the major reason for debt problems today is corporate management's past excessive optimism" (Meinert, 1991). Furthermore, the introduction of new products on the market is seldom free of forecasting bias. Golden, Miliewicz, and Herbig (1994) have concluded that actually, the majority of forecasts are never free of errors. This is not surprising as many companies may unintentionally engage in excessive optimism, especially when their existence depends on favorable forecasts. In addition to corporations being influenced by excessive optimism, individuals also display it, both, when they decide on their investments and in way they live their daily lives. Brown and Cliff (2005) have studied the influence of sentiment on the value of stock prices and have concluded that "sentiment does affect asset valuation".

Overconfidence is another bias that affects decision-making, both in the corporate world and individual investments. According to Shefrin, overconfidence "pertains to how well people understand their own abilities and the limits of their knowledge" (Shefrin, 2007). In general, people tend to overestimate their ability to perform well. This, in turn, leads to impulsive decisions as managers who think they know more than they really do are overly confident in their own abilities. Therefore, they search for less help and direction in making major decisions. Cooper, Folta, and Woo, (1995) found that new entrepreneurs tend to seek out more information before committing to decisions than do seasoned ones. This difference may be explained by the overconfidence trait exhibited by successful entrepreneurs. In itself, overconfidence can generally be viewed as a positive trait as it leads to survival both in short and long run, especially for entrepreneurs. The negativity of the bias presents itself in those situations when individuals don't recognize their limitations and therefore, make faulty decisions based on erroneous premises.

Confirmation bias is a cognitive bias, or tendency to interpret information in such a way that it confirms preconceptions, while avoiding interpretations which contradict previously held beliefs(Shefrin, 2007). Malika and Hari Das have looked at business students' perceptions of university professors' intelligence and ability as it related to gender and concluded that male students are more likely to consider male professors more apt while females are more likely to choose females. This has later been linked to confirmation bias as expressed through the fact that male students most likely can identify male characteristics easier while females do the opposite, but in the end, "both genders see success as close to their own image" (Das and Das, 2001). In the earlier studies of psychology, Baron found that confirmation bias is exhibited even when the theory being tested is a tentative one, emphasizing the influence of this particular bias on human behavior (Baron, 2001). The same bias extends to an individual base. If a consumer has a strong feeling towards a particular brand, he/she will tend to select the information that is in conjunction with the belief held. Consequently, no matter if we look at confirmation bias in context of individual or corporate decision-making, it is present in the form of accentuating what people want to believe while ignoring anything that lies outside preconceived notions.

Illusion of control is defined as the "tendency of people to believe they can control and/or influence outcomes that in reality they have no influence over" (Shefrin, 2007). Illusion of control gives people the wrong 
impression that outcome can be influenced by personal involvement when the reality is quite different. Furthermore, people tend to display overconfidence in conjunction with illusion of control, accentuating their predisposition towards error.

The familiarity heuristic suggests that peoples' ability to see events as likely to happen depends on how easily they can recall specific past information associated with that event (Shefrin, 2007). Their familiarity with the information that serves as the base for their decision clearly influences their actions. Furthermore, Ashcraft defined the familiarity heuristic as something that shows "how bias of availability is related to the ease of recall" (Ashcraft, 2006). Familiarity bias is most evident in marketing. The perceptions people have about specific brands are influenced by how familiar they are with the products associated with that brand. When making a purchasing decision, consumer confidence is usually higher if familiarity with a particular brand is higher, which might often resulted in a decision that is faster and produces results consumers feel more comfortable with.

Loss aversion or "prospect theory" is related to individual's stronger desire to avoid losses than experience comparable gains (Tversky and Kahneman, 1979). It is important to note that loss aversion will be more acute when the problem or issue is framed in negative terms, the same individuals will make a riskier decision when faced with a "negatively-framed dilemma" (Rhoads, 1997). First positively demonstrated by Tversky and Kahneman, the theory of risk aversion stipulates that losses are emotionally felt twice as strongly by people compared to comparable gains. This theory of loss aversion is present both in business and in everyday life. A study that looked at the concessions made in negotiation when the framing was alternatively posed in positive and negative frames, concluded that "a loss frame produced fewer concessions than a gain frame", proving again that individuals are less willing to negotiate when there is a potential of a loss because they are not predisposed to encounter that loss (Carnevale, 2008).

Sunk cost is an expense that has already been incurred and cannot be recovered to any significant degree. The sunk cost fallacy is often combined with risk aversion to result in decisions that are focused on minimizing already wasted resources rather than maximizing future utility. This type of decision making is based on the over commitment of individuals or managers to make an idea/ project work even if it is economically unwise. =When a bad decision can be linked to a particular person (high responsibility), the financial resources poured into a project will be escalated beyond a reasonable level. In other words, there is a significant correlation between assumed responsibility and the amount of money invested in a project (Whyte, 1986).

Previous studies have shown that biases, heuristics, and framing effects have a negative impact on decision making and result in loss of productivity and value maximization; but do students display the same amount of bias in everyday life when it comes to both financial and non financial matter? The next section of the paper will explore this question.

The behavioral survey was administered to a sample of sixty eight students at Jacksonville University in Jacksonville, FL in November 2007. Thirty one of the students are graduate and thirty seven- undergraduates. The survey had three primary purposes:

1. To look at how influenced the students are by biases, heuristics, and framing effects.

2. To see if behavioral mistakes affect graduate and undergraduate students to the same degree.

3. To see if there is any significant difference between the answers given by students to the questions that attempted to measure loss aversion and their extravert/ introvert classification, as well as the propensity to see themselves as risk takers/ avoiders; and to see if there is any significant difference between the answers given to the excessive optimism/ overconfidence questions and gender.

\section{ANALYSIS}

Excessive Optimism/ Overconfidence Bias: Six questions were asked in order to determine whether overconfidence and excessive optimism exists in students' answers. The first question asked the students to categorize themselves into better than average, average, and below average drivers. $50 \%$ of the total number of 
students replied that they are better than average while only $4.29 \%$ replied that they are worse, with the rest $45.71 \%$ stating that they were average drivers. When sorting the same answers by education level, $93 \%$ of graduate students see themselves as above average or average (58\% above average) while $97.3 \%$ of undergraduate students see themselves as above average or average ( $45 \%$ above average). The answers to this question clearly display both overconfidence and excessive optimism as only $50 \%$ of respondents can be at or above an average level at any time.

In order to see if there is a significant difference between the answers given and the few demographic variables measured above, we performed the chi-square test of independence as the data collected was categorical. The null hypothesis states that the two categories of data (i.e. excessive optimism and gender) are not related, while the alternative hypothesis states that the way participants respond to the specific question is related to the variable which we measure (i.e. gender). With a p-value of 0.15 for the Pearson Chi-square test for the relationship with the gender, we can conclude that there is no difference in the answers given to this question based upon the gender of the respondent

The second question asked whether the student thinks he/she is an above average performer when it comes to his/her job/school related activities. $81.43 \%$ of the total number of students chose yes while only $17.14 \%$ chose no (1.43\% did not respond). Breaking the numbers down by the level of education, $89 \%$ of undergraduates believe themselves to be better than average while only $76 \%$ of graduate student answered yes to this question. Albeit there is a difference in the percentage of students who answered yes and their level of education (undergraduate students seem to exhibit a greater level of excessive optimism and overconfidence), it cannot be concluded that the way the question is answered is directly related to the level of education, as the Pearson p-value for this question is 0.169. In addition, looking at the relationship between the way this question was answered and gender, we cannot reject the null hypothesis and thus, cannot conclude that there is a relationship between the two variables at a p-value of 0.874 . Therefore, we can finish with the statements that both undergraduate and graduate students are prone to make the mistake of being excessively optimistic and overconfident, given the statistical impossibility that $81 \%$ of the population is in the top half of the distribution.

The third question was designed to address the perception respondents have of their own athletic ability in comparison to their peer age group. With answers of below average, average, and above average, only 34.29\% chose the above average answer, $44.29 \%$ chose the average answer and $21.43 \%$ chose the below average. Breaking the numbers down by the level of education, only $32 \%$ of graduate students and $37 \%$ of undergraduates chose the above average answer, while $38 \%$ and respectively $45 \%$ chose the average answer. With a p-value of 0.447 , we can conclude that there is no statistical difference between the level of education and the inclination towards overconfidence and excessive optimism. One of our original assumptions was that males might be more inclined to view themselves as above average when asked specifically about athletic ability. With a total count of 39 females and 29 males who answered this question, there is a difference in the way the question was answered with $28 \%$ of females and $45 \%$ of males believing they were above average. However, with a p-value of 0.236 , we cannot state that there is a significant correlation between the levels of confidence displayed and gender, even though males generally demonstrate a higher degree of overconfidence.

The next question measured overconfidence bias by presenting the following scenario: the students had to imagine that they failed the last test. They were given the opportunity to replace the failing grade from the last exam with whatever they would get on the next exam. Knowing that they would have very little time to study and a small chance that their grade on the next exam would be higher; would they still take the risk hoping for a higher grade? $71.43 \%$ answered yes and only $28.57 \%$ answered no. From the total number of students, $67 \%$ of graduates answered yes to this question compared to the $75 \%$ of undergraduates. The small difference translated into a p-value of 0.468 , concluding that there is no statistically significant difference between the level of education and the way this question was answered. Similarly, females tended to be more confident in their ability to perform better on the next test, with $77 \%$ of them answering yes to the question compared to the $65 \%$ by males. Nevertheless, the difference is not statistically significant with a p-value of only 0.3 . We conclude that students do tend to exhibit overconfidence, even in situations where realistically, they cannot expect to perform well. Given a very small chance of success, $2 / 3$ of the respondents still answered with a yes, showing a high degree of overconfidence. 
We attempted to quantify the perception students have about how easy it would be to find a job at close to their current salary if they lost their current one. The possible choices ranged from $1=$ up to a year to $5=$ less than 2 weeks, with intermediary answers of up to six months, between one and six months, and between two weeks and six months. We would have expected the majority of the answers to revolve around the middle answer if overconfidence/ excessive optimism were lacking or alternatively, the distribution to be relatively even. However, $44.29 \%$ answered by selected the shortest two time ranges, believing they could find a job in less than a month. Of those, $12.86 \%$ believed they would only need two weeks for the same task. We would have expected graduate students to be more confident than undergraduates, given their level of experience and additional education. The results contradict this supposition. Only $6 \%$ of graduate students expected to find a job in less than 2 weeks while $16 \%$ of undergraduates have the same expectation. This might be explained by the more realistic attitude and experience of graduate students. A few of the answered were less than five; for the Chi-Square test to be valid, the expected frequencies must be greater than 5 . For example, if the expected frequency for the strongly agree/agree male cell is three and the expected cell for the agree answer is three as well, nether cell has an expected frequency of at least five and chi-square is invalid. To eliminate the conditionality, we collapsed the strongly agree and agree answers into one to obtain a frequency count of six for the above example. The collapsed answer/ combination is frequently referred to as the compact version of the Chi-square test.

The p-value of 0.23 was too low to be able to state that there is any significant difference between the answers given and the level of education. Similar to education, there is a slight difference in the answers given to this question based upon gender. 17\% of males think they will find a job in less than two weeks while only $7.69 \%$ of females feel the same. The p-value is above 0.05 and at 0.286 for the test, ergo we cannot stay that gender is a significant variable in the way the answers were given, nevertheless, there does appear to be a propensity of males to be more confident than females. Combined with the education level responses, undergraduate male students display the most overconfidence and excessive optimism when it comes to assessing their ability to find a job in a short period of time.

Finally, we have asked an investment related question to see if there is a propensity to be excessively optimistic and overconfident extends into the field of personal investments. The question looked for the general reason for the best investment decision of the respondent with the following choices: good advice, strong market/ fortunate timing, own skill and intelligence, and luck. We would have expected the most prevalent answer to be own skill and intelligence due to the strong overconfidence displayed in the prior question. To our surprise, only $14.29 \%$ of people have chosen this answer, with the majority, $62.86 \%$, splitting the answers between good advice $(28.57 \%)$ and good market performance $(34.29 \%)$. The graduate students seem to be more confident in their investment abilities, with $24 \%$ attributing good performance to own skill and intelligence while only $8 \%$ of undergraduate students chose this answer. Even though the p-value was not low enough to signify a statistically significant difference, with a value of 0.057 for the original test and 0.079 for the compact version, it is the closest we have encountered so far to identifying a relationship between the two variables. Gender wise, there is almost no difference in the answers given by males and females. $15.7 \%$ of females and $14.4 \%$ of males attribute skill and intelligence to good investment decisions. Unlike most of the other questions that show a strong tendency to exhibit overconfidence and excessive optimism, this question did not show the same inclination. This may be attributed to the fact that investment requires specialized skills and most people do not tend to believe they have those skills unless specifically trained for it. Similar to the question about athletic ability, investments require objective measurements, making it harder for respondents to exaggerate their aptitude, thus making them less susceptible to displaying the behavioral mistakes of being too confident or overly optimistic.

Illusion of Control Bias: Although we did not specifically concentrate on measuring the presence of the illusion of control bias, we desired to determine if students displayed it, especially given the fact that it usually accompanies overconfidence and excessive optimism. The following question was asked: do you think you are more likely to win the lottery if you pick the numbers yourself than a quick pick? With the answers being strongly agree, agree or strongly disagree, $10 \%$ of students answered strongly agree, $30 \%$ agree and $57.14 \%$ strongly disagree, with $2.86 \%$ not answering the question. Graduate students are more prone to believe they can control events, with $48 \%$ choosing one of the first two answers while only $35 \%$ of undergraduates chose the same answers. The p-value for the chi-square test stands at 0.518 , making the difference statistically insignificant. If the students had a tendency to 
display illusion of control, they would have answered agree or strongly agree to this question. A combined $40 \%$ did choose one of the two answers while almost $60 \%$ did not, showing that the students do not present a strong tendency to be influenced by the illusion of control misconception.

Confirmation Bias: Similar to the illusion of control bias, we asked a question to see if students will give an obvious result and engage in making this behavioral mistake. The question asked how willing the students were to accept an idea that would probably result in a positive outcome if it was contrary to the current beliefs held by them. The answers given were: not willing at all, probably willing, and extremely willing. Answering not willing would have proved that students did engage in confirmation bias, making a choice based on previously held beliefs rather than the objectivity of the outcome. Only $11.43 \%$ of the respondents chose the answer stating not willing at all and only $8.57 \%$ chose the answer extremely willing, with the majority, $80 \%$ stating that they would probably be willing to make the decision even if it was against what they previously believed. Graduate students were slightly less prone to get engaged in confirmation bias, with $9 \%$ choosing the first answer while undergraduate students' same answer measures $13.51 \%$. However, the p-value for the chi-square test is high, at .518 making it impossible for us to say that education is related to the way this question was answered. Of particular interest in this question is the $80 \%$ of the students who respondent probably likely. If they indeed make the decision despite what they believed, then we can safely say that very few people were subject to this mistake. If however, the same $80 \%$ decide to make the decision in accordance with their current beliefs, then the majority may end up engaging in confirmation bias.

Familiarity Heuristic: Two questions were asked in order to assess the extent to which students use familiarity to make decisions. The first question asked if students were to select a random word from the dictionary, would it be more probable they would have encountered a word that started with an $\mathrm{R}$ compared to the $3^{\text {rd }}$ letter in the word being the R. Most of us can recollect words that start with an $\mathrm{R}$ faster than we can think about words that have $\mathrm{R}$ in the middle. Therefore, if most students answered starts with $\mathrm{R}$, then they would be making the mistake of recalling familiar words. $48.57 \%$ of the total number of students answered that they would be more probable to find a word that stares with $\mathrm{R}$ and $51.43 \%$ answered that $\mathrm{R}$ is the $3^{\text {rd }}$ letter. Out of the total number, $45 \%$ of graduate students and $51 \%$ of undergraduate students chose the answer with the first letter of the word. The p-value for the Pearson chi-square test is 0.611 , showing no difference in the way the question was answered and the level of education. Overall, the answers to this question showed that familiarity heuristic was not present in either graduate or undergraduate students' answers.

Next, an investment related questions were asked. It attempted to see if students who frequently shop at Starbucks believe that buying stock in Starbucks would represent a good investment choice. Four possible answers were offered to choose from: strongly agree, agree, disagree, and strongly disagree. $34.29 \%$ of the total number of students answered with agree and $2.86 \%$ with strongly agree, bringing the total number of positive answers to $37.25 \%$. Conversely, the total number of students who answered disagree or strongly disagree was $62.86 \%$. When looking at the distribution of answers in relationship with the level of education, we can see that the number of graduate students who answered agree or strongly agree is $33.3 \%$ while the number of undergraduate students is $40.54 \%$, undergraduate students showing a slightly higher tendency to exhibit the existence of familiarity heuristic. The difference, however, is not significant with a p-value of 0.774 . We can conclude that the two questions asked did not show a strong presence of the behavioral mistake known as familiarity heuristic.

Loss Aversion: Knowing that in general, people are known to be loss averse, we have asked five different questions to determine if students encounter the same behavioral pitfall in their daily lives as the general population. The first question stated that the students have already won $\$ 1,000$. They had a choice of either receiving another $\$ 500$ without doing anything or they could flip a fair coin and receive another $\$ 1,000$ if heads come up or lose the original \$1,000 in case tails come up. If loss averse, most people would pick the first choice. Indeed, 94.29\% chose to forgo the potential greater gain because of the greater risk and only $5.71 \%$ chose to gamble with the toss and hope for the better outcome. $93 \%$ of graduate students and 97\% of undergraduate students chose the first answer with $6.4 \%$ and respectively $2.7 \%$ choosing answer $\mathrm{b}$. The difference is not significantly different with a p-value of 0.453 . Another relationship we measured was between the answer to the risk aversion questions and the type of personality the students considered themselves to be: extrovert versus introvert and risk taker versus risk avoider. Although 38 students consider themselves to be extroverts, only $5.2 \%$ chose the risky alternative, showing that the label of 
extrovert does not guarantee the acceptance of greater risk. The p-value of 0.722 that measures this relationship reinforces the conclusion that there is no statistical correlation between the type of personality and the choice of greater risk. Furthermore, although 28 students described themselves as risk takers, only 1 (3.57\%) chose the risky alternative. Therefore, we could not conclude that there is a relationship between the type of personality (risk taker/ avoider) and the inclination to choose a greater amount of risk when given the opportunity. The p-value for the Pearson chi-square test in this situation was 0.761 . Consequently, we can state that even though a large number of students perceive themselves to be extroverted and risk takers, their respective answers to this particular question demonstrate that they are loss averse, regardless of how they perceive themselves to be.

Unlike the first question that addressed financial gain, the second question offered the students to check a box at the end of the final exam and potentially get 10 extra points. If, however, the number of students who check the box is greater than $1 / 2$ of the class, the professor will deduct 10 points from the final score. The students had to decide if they would check the box or not. $48.57 \%$ chose to check the box and $51.43 \%$ chose not to. Unlike the previous question which shows an overwhelming tendency to try to avoid a loss, this question has an almost even split of answers, making it impossible for us to conclude that students are loss averse when it comes to their grades. It appears that they are more willing to gamble in a situation that does not involve financial gain or loss. $41.6 \%$ of the total number of student labeled themselves as risk takers and in this case, the number correspondent better to the answers given than in the previous question with a slightly higher percentage (48.57\%) actually choosing the risky alternative. Nevertheless, there is no relationship either between the risk taking propensity and the way the answer given, or between extraversion and the answers, with p-values of 0.549 and 0.180 respectively.

The next question addressed risk aversion in the context of the work environment. The students were presented a situation in which the official sick day policy at the company they work in allows them not to go to work without calling in sick. If the boss (who travels $80 \%$ of the time) happens to be away, the workers will not get penalized and stay home without using a sick day. If, however, the boss happens to be at work that day, they will be penalized 3 sick days. The students had to make the choice between coming to work even though they may be forgoing free vacation time and not coming to work but take the risk of losing three sick days. $81.43 \%$ of respondents displayed loss aversion and decided to come to work while only $18.57 \%$ chose to stay home and take the risk. There is no difference in the answers given and the level of education, with $83 \%$ of graduate and $81 \%$ of undergraduate students choosing to come to work. The lack of a relationship is validated by a p-value of 0.763 . Also, there is no relationship between the risk aversion or extraversion and the answer chosen. Similar to the answers given to the first question that involved monetary loss, this question shows that despite the classification the students gave themselves ( $41 \%$ being risk takers), the students still displayed loss and risk aversion. With a p-value of 0.443 between the extroversion and the answers given to this question and 0.992 between risk taking and the answers, we cannot conclude that the way the students answer this question corresponds to the way they labeled themselves to be, either extrovert/introvert or risk taker/ risk avoider.

Subsequently, the students were asked to choose between disposing of one stock in their portfolio, either the one that was $50 \%$ up or the one that was $50 \%$ down. $38.57 \%$ would sell the gainer and $58.57 \%$, the loser. Although selling the loser is the recommended action in this situation, almost $40 \%$ of respondents did not choose it, displaying loss aversion. Selling a looser would make economic sense but it would also mean recognizing making a mistake. Therefore, almost half of the interviewees preferred to choose the economically inferior stock, showing the existence of loss aversion. There is no relationship between the way the students answered this question and their self perception of being an extrovert or an introvert. Similarly, there is no relationship between the variable and the self perception of risk aversion. With p-values of 0.83 and 0.852 , we can conclude that the aversion to loss as measured by this question is not affected by either the perception students have of being introvert/extrovert or risk takers/avoiders.

Finally, the last question asked in the risk aversion category was a statement related to building a guaranteed income from investments even if the rate of return is low. $37.14 \%$ chose the strongly agree answer and $58.57 \%$ somewhat agreed to this statement, bring the total positive answer to $95.71 \%$, with only $4.29 \%$ selecting somewhat disagree or strongly disagree. Unlike all the other relationships examined during this survey, this was the only question that found a statistically significant relationship between the answers given to this question and the 
risk taker/avoider categorization students chose for themselves. With a p-value of 0.021 for the compact version, we can conclude that the relationship between the two variables exists and that students, who perceive themselves to be risk avoiders, tend to choose a less risky alternative for investment in comparison with students who see themselves as risk takers. The relationship between the answers given and the degree of extroversion were not significant with a p-value if 0.385 for the compact version of the question.

Sunk Cost fallacy: The last set of questions addressed is the sunk cost fallacy. Four question and/or statements were offered to the students to assess the degree to which sunk cost influences both their financial and nonfinancial decision making. The $1^{\text {st }}$ situation stated that the student has already spent $\$ 20,000$ in a house improvement project that did not result in any positive improvement on the value of the home. There is a possibility that the project could be salvaged if another $\$ 20,000$ is invested in (additional $100 \%$ ). We wanted to know if given the fact that $\$ 20,000$ were already spent on this investment, how likely it is that the additional money will be invested, even though the project may not result in success. Only $4.29 \%$ of the total number of respondents answered very probable, making the mistake of basing a decision on already spent money that cannot be recovered or in other words, making sunk cost part of the decision making process. $32.86 \%$ responded it was probable that they would spend the additional money and the majority, $62.86 \%$ decided that it was very improbable. Overall, the majority of the students did not make the mistake of incorporating sunk costs into a future decision. While only $29 \%$ of graduate students chose the very probably or probable answers, $43.24 \%$ of undergraduate students made the same choice. With a p-value of 0.226 for the chi-square test, we cannot conclude that the level of education affected the answers given even though it appears so from the higher percentage of undergraduate students who engaged in the sank cost fallacy.

The second question asked the students to make a decision about how important the purchase price for a home that was bought at the pick of the Jacksonville real estate market is on the asking price in a buyers' market in which the house is already worth less than it was purchased for a few years ago. Conceptually, this question is exactly the same as the previous one but the answers given could not be more different. While almost $2 / 3$ of the respondents avoided basing a decision on sunk cost in the previous question, the opposite is true of this one. 58.57\% say that the purchasing price (a sunk cost) is very important, with another $31.43 \%$ selecting somewhat important and only $10 \%$ completely disregarding the original purchasing price. There is almost no difference in the way this question was answered between the undergraduate and graduate student with $89 \%$ and $90 \%$ respectively falling victim to the sunk cost fallacy. One potential explanation of the difference in answers between the two questions is the amount of money involved (significantly higher for the current question) and the outside influences, such as a payoff of a mortgage, that may not give the respondents a choice in the selected answer. Nevertheless, the sunk cost fallacy is evident in the answers given to this question.

The next question asked the students to assess the importance of a non-refundable rent deposit on a condo near the beach when a better living place was found after the $\$ 1,000$ deposit has already been paid. One third of the students (34.29\%) chose to ignore the sunk cost while the rest, $64.29 \%$ made their living decision by incorporating the sunk cost (1.43\% did not answer). Similar to the previous question, the answers to this one show a tendency of students to make a decision based on a cost that cannot be recovered and should not be incorporated into the analysis. Although there is a difference in the answers given between the two groups, it is not significant enough to conclude that graduate students are less inclined to separate sunk costs and exclude them from the decision making process. Nevertheless, $25 \%$ of graduate students compared to $43 \%$ of undergraduates made the mistake.

Finally, we asked the students to decide whether they would be more willing to go to a basketball game in a blizzard if they purchased the tickets or if they obtained them for free. $90 \%$ of the students answered that they would be more willing to go to the game regardless of the inconvenience if the tickets were purchased, showing one more time that sunk cost does play a role in the decisions students make. The level of education did not appear to affect the answer given with $91.6 \%$ of undergraduate students being more willing to go to a game if they incurred a cost, compared to $93.5 \%$ of graduate students who chose the same answer. Overall, with the exception of the first question, the students showed a strong tendency to consider sunk costs when they make decisions. 


\section{CONCLUSIONS}

Although our research was not comprehensive enough to examine all sources of bias and heuristics, we were able to detect a few clear biases among and between business college students.

The 45-question survey we presented to the undergraduate and graduate and was designed to assess and measure behavioral mistakes students might engage in when they make both financial and non-financial decisions. Although there were a number of behavioral biases and heuristics contained in the survey, we focused on overconfidence and excessive optimism, loss aversion, familiarity, and sunk cost fallacy, as well as an initial overview of illusion of control and confirmation bias. However, it should be noted that our observations may also be subject to bias. Our research is based on only one questionnaire and was administered to a limited number of students, so any statistical inferences drawn may be spurious. With that caveat, the following conclusions can be extracted from the analysis of the survey:

- $\quad$ Students are extremely optimistic and overconfident when they are asked to assess their driving ability and job/school performance but are less optimistic about athletic ability or investment ability. Consequently, students are less disposed to make the mistake of being overly confident and optimistic when there is more objectivity involved in making the assessment.

- $\quad$ Students did not display illusion of control tendencies

- $\quad$ Although some of the students engaged in confirmation bias, most answers could be interpreted in a number of ways, making it impossible to judge the degree of the bias present in students' decision making process.

- $\quad$ Students did not show a tendency to be subject to the familiarity heuristic.

- $\quad$ Students tend to be as risk averse as the general population. This is specifically true when there is financial gain/loss involved. However, students tend to be less risk averse when it comes to their grades.

- It does appear that the sunk cost fallacy is alive and well in college students when making ex ante based decisions.

- $\quad$ Students, in general, appear to exhibit "bounded rationality" in their decision making behavior.

- $\quad$ This research provides the theoretical underpinnings for the further morphing of standard classical finance into the behavioral finance paradigm.

\section{REFERENCES}

1. Arkes, Hal \& Blumer, Catherine. (1985) The Psychology of Sunk Cost Organizational Behavior and Human Decision Process 35, 124-140

2. Ashcraft, M.H. (2006).Cognition. Upper Saddle River, New Jersey; Pearson Education Inc..

3. Baron, J. Thinking and deciding. Cambridge: Cambridge University Press, 1988.

4. Belsky, Gary and Thomas Gilovich Why Smart People Make Big Money Mistakes and How to Correct Them. Simon \& Schuster, 1999. New York, NY.

5. Brown, Gregory and Michael Cliff. Investor Sentiment and Asset Valuation. The Journal of Business. Vol. 78. Iss. 2. Chicago, March 2005. Pg. 405-36.

6. Cooper, A. C., T. B. Folta, and C. Woo Entrepreneurial Information Search, Journal of Business Venturing 10, 1995. pages 107-120.

7. Einhorn, H.J. and Hogarth, R.M., Confidence in judgment: persistent of the illusion of validity, Psychological Review, Vol. 85. 1978. pp. 395-416.

8. Epstein, Gene. The Myth of Rationality: What Really Drives Economic Decisions. Barron's. V.74 (October 17 1994). Pages 28-9.

9. Golden, James, Miliwicz, John, and Paul Herbig. Forecasting: Trials and Tribulations. Management Decision. Vol. 32, Iss.1. London, 1994. pages 33-4.

10. Kahneman, D. \& Tversky, A. (1979). Prospect Theory: An Analysis of Decision under Risk. Econometrica 47, 263-291.

11. Kent Daniel and Sheridan Titman. Market Efficiency in an Irrational World. Financial Analysts Journal. Nov/Dec 1999. vol 55. Iss.6 Pages 28-40. 
12. Ko, Jeremy and Zhijian Huang. Arrogance can be a virtue: Overconfidence, Information Acquisition, and market Efficiency. Journal of Financial Economics. V84. N2.Pages 529-60.

13. Larrick, Richard, Burson, Katherine, and Jack Soll. Social Comparison and Confidence: When Thinking You are Better than Average Predicts Overconfidence. Organizational Behavior and Human Decision Processes v. 102 no. 1 (January 2007) pages. 76-94

14. Mallica Das and Das Hari. Business Student Perceptions of best University Professors: Does Gender Role Matter?. Sex Roles. Vol. 45. iss 9/10. New York, 2001. Pages 665-12.

15. Mehta, Nitin. Investigating Consumers' Purchase Incidence and Brand Choice Decisions Across Multiple Product Categories: A Theoretical and Empirical Analysis. Marketing Science. Vol. 26. N2. March/April 2007. Pages 196-217.

16. Meinert, John. Financial Advice from a Business Veteran. Journal of Accountancy. New York. Vol. 171. Iss. 6 June 1991. pages 134-4.

17. O'Creevy, Fenton, M., Nicholson, N. Soane and E. and Willman, P. Individual and Contextual Influences on the Market Behaviour of Finance Professionals (ESRC Conference Paper), 1998.

18. Park, W., Lessig, P. (1981). Familiarity and its impact on consumer decision biases and heuristics. Journal of Consumer Research, 8, p. 223-230."

19. Peter J Carnevale. Group Decision and Negotiation. Dordrecht: Jan 2008. Vol.17, Iss. 1; pg. 51, 13 pgs

20. Rhoades, Kelton. (1997) Loss Aversion, Risk, \& Framing: The Psychology of an Influence Strategy", Russo and Schoemaker. "Managing Over-Confidence", Sloan Management Review, 1992. pages 7-17.

21. Shefrin, Hersh. Behavioral Corporate Finance. Decisions that Create Value. McGraw- Hill/Irwin. New York, 2007.

22. Strang, David and Michael Macy. In Search of Excellence: Fads, Success Stories, and Adaptive Emulation. The American Journal of Sociology. Vol 107. Iss. 1. Chicago, July 2001. pages 147-36.

23. Toshino, Masashi and Megumi Suto (2004), Behavioral biases of Japanese institutional investors Journal of Economics and Business 190, Kobe University, July, pp.15-31

24. Tversky, A. \& Kahneman, D. (1991). Loss Aversion in Riskless Choice: A Reference Dependent Model. Quarterly Journal of Economics 106, 1039-1061.

25. Whyte, Glen. (1986) Escalating Commitment to a Course of Action: A Reinterpretation Academy of Management Review Vol. 16, p. 27-44.

26. Wikipedia http://en.wikipedia.org/wiki/Illusion of control. 